\title{
ERRATUM
}

\section{Heat-assisted magnetic recording by a near-field transducer with efficient optical energy transfer}

W. A. Challener, Chubing Peng, A. V. Itagi, D. Karns, Wei Peng, Yingguo Peng, XiaoMin Yang, Xiaobin Zhu, N. J. Gokemeijer, Y.-T. Hsia, G. Ju, Robert E. Rottmayer, Michael A. Seigler and E. C. Gage

Nature Photonics 3, 220-224 (2009); published online 22 March 2009, corrected after print 24 March 2009.

In the version of this article originally published, in the caption to Fig. 4a the distance between the dashed lines was incorrectly given as $0.050 \mathrm{~nm}$; this should have read $0.050 \mu \mathrm{m}$. The error has now been corrected in the HTML and PDF versions. 